\title{
Effects of Intramolecular Basis Set Superposition Error on Conformational Energy Difference of 1,2-Difluoroethane and 1,2-Dimethoxyethane ${ }^{\dagger}$
}

\author{
Young-Kyu Han, Kyoung Hoon Kim, Sang-Kil Son, and Yoon Sup Lec \\ Department of (hemistry and School of Holecular Science (BK2J). K1/ST' Daejeon $305-701$, forea \\ Receivedilpril 8. 2002
}

\begin{abstract}
The conformation dependences of basis set superposition errors (BSSE) for 1.2-difluoroethane (DFE) and 1.2dimethoxyethane (DME) molecules have been estimated using counterpoise method at the Möller-Plesset second order perturbation (MP2) level of theory with various basis sets, assuning that all BSSE dependences on conformations are due to the change in CC bond. The BSSE on the energy differences between eclipsed and gauche forms of DFE are in the range of 0.2-1.2 kcal/mol and those between local minima. gauche and anti forms, are less than $0.2 \mathrm{kcal} / \mathrm{mol}$. For the larger DME molecule, the BSSE differences between local ninima are still less thim $0.4 \mathrm{kcal} / \mathrm{mol}$, but may not be ignored compared to the energy differences of $0.2-3.0 \mathrm{kcal} / \mathrm{mol}$ between conformers.
\end{abstract}

Key Words : Intramolecular BSSE. Counterpoise correction. MP2 calculations. 1.2-Difluorocthane. 1.2Dimethoxyethane

\section{Introduction}

Theoretical studies on conformations imply that using extended basis sets with diffise and multiple polarization functions is more important than the high-level treatment of electron correlations. ${ }^{1-4}$ An acceptable procedure for estimating the relative energies between conformers in a molecule is to optimize geometry at the MP2 (or HF) level of theory using double zeta polarized basis set and perform single point calculations at MP4 (or MP2) using triple zeta multiple polarized basis set augmented with one diffuse sp set. ${ }^{+.5}$ The variation of the basis set superposition error (BSSE) is seldom considered in the calculations of conformational energy differences although it is not difficult to recognize the existence of BSSE which varies with conformation. ${ }^{4}$ There are many studies inrestigating the BSSE in intermolecular interaction between two closed-shell molecules. but no systematic studies for the intramolecular BSSE effects on conformations have. to the best of our knowledge. been reported. We suggest a method of estimating BSSE differences among different conformations and apply the method to stidy the BSSE for 1.2-difluoroethane (DFE) and 1.2dimethoxyethane (DME). Those molecules are selected for their gauche effect where polar substituents cause the preferred conformation about a C-C bond to switch from a trans to a gauche form.

\section{Method and Calculations}

One can eliminate BSSE by increasing the basis set until conformation energy differences converge to the desired accuracy: but such an approach is slowly convergent and

\footnotetext{
I) Jedicated to the late J'ofessor Sang Chul Shim in menory of his great contribution to photochemistry and organic chemistry

"Cortesponding Author. e-mail: yslex t̂mail.kaist ac.kr
}

viable only for small systems. The usual practice is to estimate BSSE for the given basis sets using the counterpoise (CP) method. ${ }^{67}$ Although the CP method can be applied separately to every atom in a molecule for all conformations. the resulting calculation will not be practical for most molecules of interest. In this work. we evaluate BSSE associated with the one $\mathrm{C}-\mathrm{C}$ bond in order to obtain corrections for the conformational energy differences under the assumption that this C-C bond contains the major differential BSSE for differing conformers. Since conformation energy is concented with the rotation of a single bond in a molecule, the C-C bond in this case, it is meaningfil to estimate BSSE contained in the interaction energy (or dissociation energy) of the $\mathrm{C}-\mathrm{C}$ bond

The BSSE present in the interaction energy of the C-C bond can be calculated as

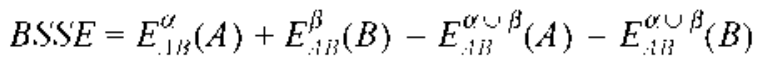

where the electronic energy of a molecular system $M$ at geometry $G$ computed with basis set $\sigma$ is defined as $E_{G}{ }^{\sigma}(M)$. Eq. (1) is exact within the CP scheme where fragments $A$ and $\mathrm{B}$ have constant geometries. Since geometries of fragments are usually quite similar anong conformers. a reasonable correction of BSSE for conformational energies can be obtained by comparing BSSEs calculated by Eq. (1) for various conformers. The main quantity of interest here is the variation of BSSE antong niany conformers and not the BSSE itself of Eq. (1). When the geometry relaxations of the fragments are substantial. BSSE and geonetry relaxation should be considered simultaneously. One extreme case is that of the bonding dissociation energy (BDE). In such cases. the BDE corrected for BSSE by the CP method (BDE_CP) can be expressed $\mathrm{as}^{\mathrm{N} .9}$

$$
\begin{aligned}
& \text { BI)I: }\left(P^{P}=\right.
\end{aligned}
$$

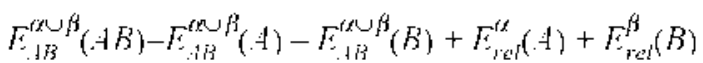


where $K_{r e l}^{\alpha}(A)=t_{A B}^{\alpha}(A)-H_{A}^{\alpha}(A)$ and $K_{r e f}^{\alpha}(B)=K_{A B}^{\alpha}(B)$ $-l_{B}^{\alpha}(B)$ are the fragment relaxation encrgies corresponding to the energy penalty for distorting the fragments from their isolated geometries to the ones in the complex. While there can be many debates about the utility of Eq. (2) as a better estimate of BDE in general due to the presence of BSSE in the relaxation process of each fragment. BDE_CP is used here to serve as a convenient reference point in comparing many different conformations. Bond dissociation is a convenient reference point since the relaxed fragments $A$ and $B$ are almost identical for all conformers. The validity of the present scheme of using BDE_CP of Eq. (2) as the reference strongly relies on the observation that fragments A and $\mathrm{B}$ differ very litle among conformers. i.e. relaxed geometries of a given fragment are almost identical among conformers under consideration although they may differ substantially from the geometry of minimum energy:

The CP correction provides neither upper nor lower bounds for BSSE ${ }^{7.10-12}$ We expect that our approach of employing the CP method to estimate BSSE on the conformational energy difference is rather reliable since no bond breaking is involved. We have estimated the intramolecular BSSE effects on the energy differences among the fluorine-lluorine gauche. anti. and eclipsed conformations of DFE and cnergy: differences among nine conformers of DME. Boh for DFE and DME. only the fragmentation and thus the BDE of the central $\mathrm{C}-\mathrm{C}$ bond is treated by the $\mathrm{CP}$ method.

Electronic energies of DFE have been calculated at the MP2 level of theory using 6-3l lG. 6-3 l l++G. 6-3l JG(d.p). $6-311++G(d \cdot p) .6-311 G(2 d \cdot 2 p) .6-311++G(2 d \cdot 2 p) .6-311 G$ (3d.3p). 6-3l $\mathrm{l}++\mathrm{G}(3 \mathrm{~d} \cdot 3 \mathrm{p})$. 6-3ll G(3di.3pd). and 6-3l l++G (3dr.3pd) basis sets. These basis sets are selected to show the role of sp diffuse set denoted by ++ and the polarization (additional functions in parentheses) sets cxplicitly. The outcrmost dexponent of 0.4375 for the fluorine atom and the outcrmost p exponent of 0.1875 for the hydrogen atom have significant diffuse character in the basis sets. 6-31 JG(3d.3p). $6-311++\mathrm{G}(3 \mathrm{~d} .3 \mathrm{p}), 6-311 \mathrm{G}(3 \mathrm{df} .3 \mathrm{pd})$, and $6-311++\mathrm{G}(3 \mathrm{df} .3 \mathrm{pd})$.
Density functional theory (DFT) calculations with B3LYP functionals were performed with $6-311 \mathrm{G}$ and $6-311++\mathrm{G}$ (3df.3pd) basis sets. We optimized geometrics of the DME molecule at the MP2 level of theory using D95** basis sets. followed by a scrics of MP2 singlc-point calculations using extended D $95+(2 \mathrm{dr}$. p) basis sets. All calculations have been performed with the GAUSSIAN94 suite of programs. ${ }^{13}$

\section{Results and Discussion}

A. 1,2-Difluorocthane (DFE). Table 1 shows BDE_CPs corresponding to the fission of DFE into two $\mathrm{CFH}_{2}$ fragments for anti. celipsed. and gauche lorms of the DFE conformers with the BSSE correction. The differences of BDEs betwcen conlormers without BSSE correction are equivalent to the energy dillerences between the conformers of DFE. The BSSEs in threc conformers lor the various basis sets are plotted in Figure I where the abscissa roughly rellects total number of basis linctions in the basis set. While the absolute valucs of BSSEs contain many crrors mainly from relaxation process. the relative values or trends are uscful. The same relative values can also be oblained by cmploying Eq. (1) without any reference to BDE_CP. The intramolecular BSSE decreases. as the size of basis set increases. From about 9- $10 \mathrm{kcal} / \mathrm{mol}$ to about $3 \mathrm{kcal} / \mathrm{mol}$. The decrease of BSSE is not monotonous since the contribution of the sp diffuse sets is larger than that of the additional polarization sets. The BSSE of fluorine-fluorine cclipsed structure is smaller than that of gauche or anti form due to the fact that the distance between $\mathrm{CFH}_{2}$ fragments in the cclipsed form is longer than those of other forms as shown in Table I. reflecting larger repulsions between two $\mathrm{F}$ atoms in the celipsed structure. The BSSE differences between two local minima cannot be explained by the C-C bond lengths. implying the presence of subtle ligand effects.

The calculated BSSES in the internal rotation barricr of DFE (E(c)lipsed)-E(gauche)) are in the range of 0.2-1.2 $\mathrm{kcal} / \mathrm{mol}$ for the various basis sets. As shown in Figure 2. the

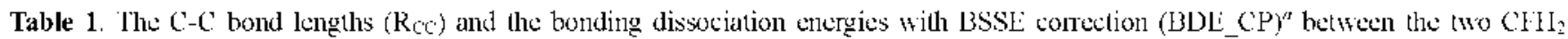

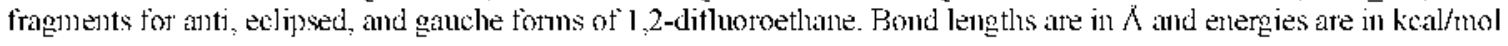

\begin{tabular}{|c|c|c|c|c|c|c|c|c|c|}
\hline \multirow{2}{*}{ Basis set } & \multicolumn{3}{|c|}{ Anti } & \multicolumn{3}{|c|}{ Liclipsul } & \multicolumn{3}{|c|}{ Gauche } \\
\hline & $\mathrm{R}_{\mathrm{co}}$ & BSSE & BDL_CP & $\mathrm{R}_{x}$ & BSSE & BDL_CP & $\mathrm{R}_{\mathrm{r}}$ & BSSE & BDE_CP \\
\hline $6-311 \mathrm{G}$ & 1.517 & 100 & 84.5 & 1.546 & 8.8 & 760 & 1.506 & 100 & 84.1 \\
\hline (B.YI.YT) $)^{h}$ & & $(4.3)$ & (91.3) & & $(3.6)$ & $(83.0)$ & & $(4.2)$ & $(91.3)$ \\
\hline $6-311++\mathrm{C}$ & 1.518 & 8.2 & 86.4 & 1.547 & 7.6 & 77.6 & 1.505 & 8.4 & $86 . .3$ \\
\hline $6-31 \mathrm{IG}(\mathrm{d}, y)$ & 1.515 & 6.8 & 91.6 & 1.547 & 5.9 & 84.6 & 1.505 & 6.6 & 22.0 \\
\hline $6-311++(\mathrm{Y}(\mathrm{d}, \mathrm{p}))$ & 1.516 & 4.8 & 92.8 & 1.548 & 4.3 & 85.7 & 1.504 & 4.9 & 93.4 \\
\hline $6-311 \mathrm{G}(2 \mathrm{~d}, 2 \mathrm{p})$ & 1.510 & 5.7 & 93.2 & 1.543 & 5.3 & 86.3 & 1.499 & 5.6 & 93.7 \\
\hline $6-311++(\mathrm{y}(2 \mathrm{~d}, 21))$ & 1.510 & 4.1 & 94.2 & 1.543 & 38 & 87.0 & 1.498 & 4.1 & 24.8 \\
\hline $6-311 \mathrm{G}(\hat{3} \mathrm{~d}, 3 p)$ & 1.512 & 4.4 & 94.8 & 1.545 & 4.1 & 88.1 & 1.501 & 4.5 & 95.6 \\
\hline $6-311++(\mathrm{s}(3 \mathrm{~d}, 3 \mathrm{j}))$ & 1.513 & 3.8 & 95.4 & 1.545 & 3.7 & 88.3 & 1.501 & 3.9 & 96.1 \\
\hline 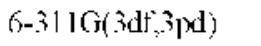 & 1.510 & 3.3 & 26.6 & 1.543 & 3.1 & 900 & 1.500 & 3.4 & 97.5 \\
\hline 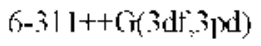 & 1.311 & 2.7 & 97.3 & 1.544 & 2.6 & 90.4 & 1.499 & 2.7 & 98.1 \\
\hline$(\mathrm{B} \text {.IIYT })^{h}$ & & $(0.8)$ & $(91.2)$ & & $(0.8)$ & $(84.6)$ & & $(0.8)$ & $(92.2)$ \\
\hline
\end{tabular}

"AII BDF_CP values are absolute values. "Values from DFT calculations with J3.3I.YP tunctionals with the basis set above are in perenthesis. 


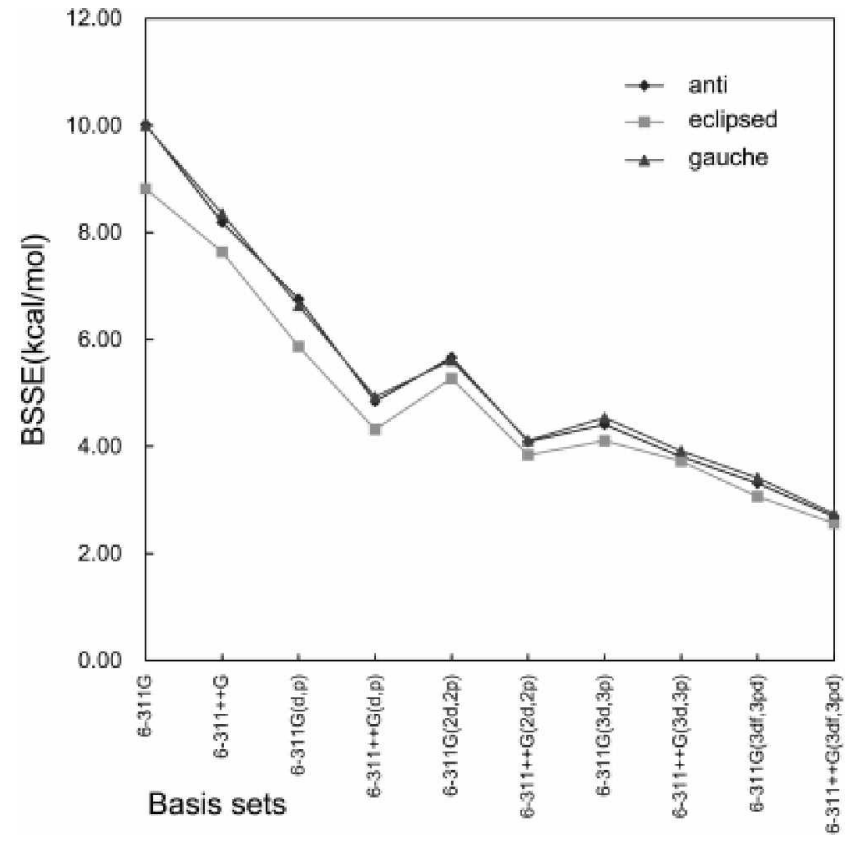

Figure 1. BSSLis in the anti. gatuche, and eclipsed structures of the 1,2-difluoroethane (DFF) for various basis sets.

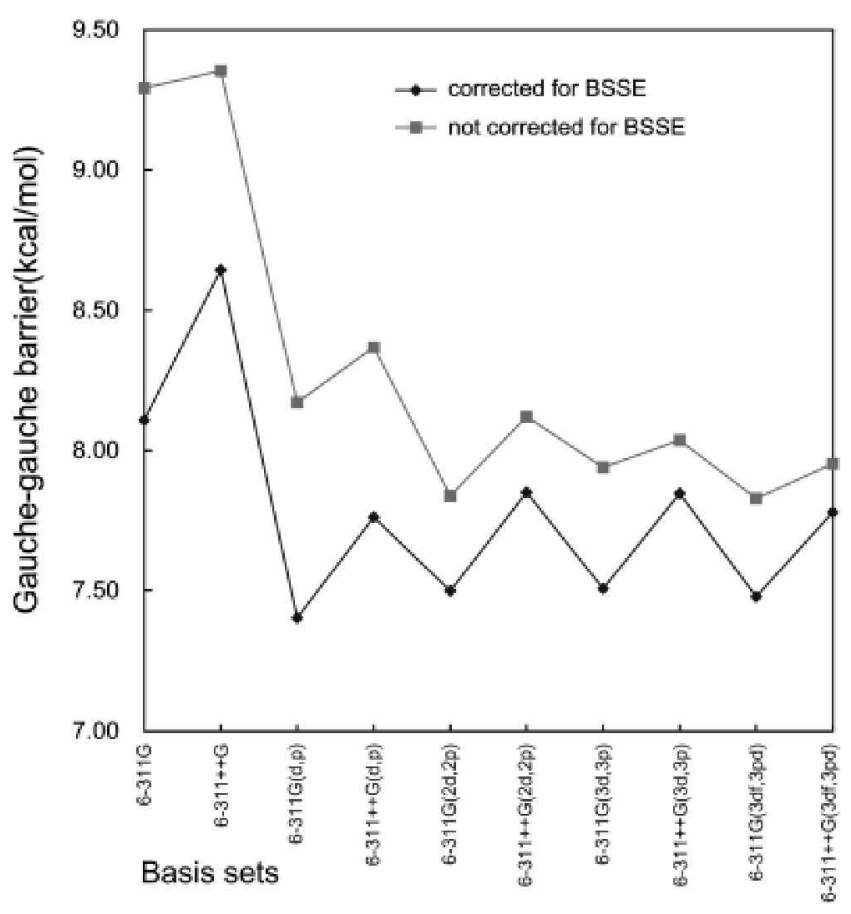

Figure 2. The hatyet height for the intenal rotation. F(eclipsed)Figauche), of DFF, at the MP2 level of theor using varnous basis scls.

BSSE corrections alwars decrease the barrier since the BSSE is smallest in the eclipsed form. The sp diffuse sets also decrease BSSE significantly and increase the barrier by about $0.3 \mathrm{kcal} / \mathrm{mol}$ uniformly. Howerer. the BSSE effects on the energy difference between two local minima. gauche and anti structires, are relatively small. being less than $0.2 \mathrm{kcal} /$ $\mathrm{mol}$. The BSSE effects on the energy differences. E(gauche)$E$ (anti), plotted in Figure 3 suggest an interesting feature

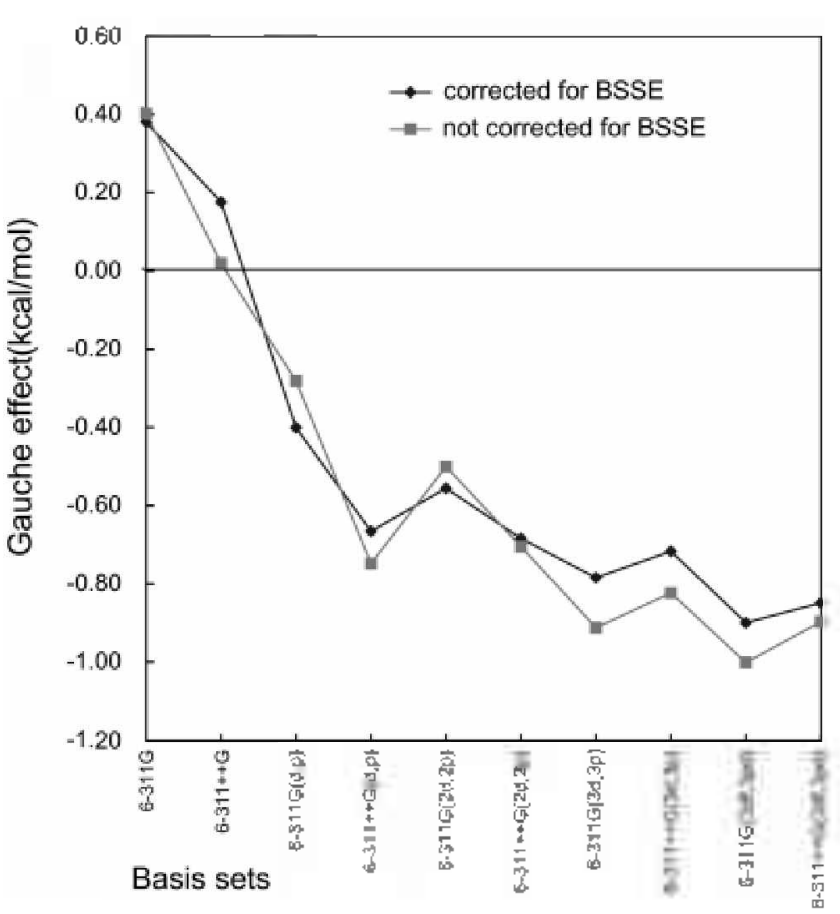

Figurc 3. The gauche efrect, F.(gauche)-F(ant1), of DFF, at the MP2 lavel of theory using various basis sels.

about the role of sp diffuse sets. Previous theorctical studics for the DFE molccule indicate that the sp diffuse functions arc crucial for the accurate estimate of the $\Delta \mathrm{E}$ ( $\mathrm{E}$ (gauche)$E(a n t i))$ valuc. ${ }^{214}$ which is certainly truc for the basis sets of moderate size in popular use. The change of $\Delta \mathrm{E}$ from 6$31] \mathrm{G}(\mathrm{d} . \mathrm{p})$ to $6-3 \mathrm{l} \mathrm{I}+\mathrm{G}(\mathrm{d} . \mathrm{p})$ is $-0.50 \mathrm{kcal} / \mathrm{mol}$. which is larger in magnitude than the change of $\Delta \mathrm{E} .-(0.20 \mathrm{kcal} / \mathrm{mol}$. from 6-3]IG(d.p) to 6-3]IG(2d.2p) basis set. However. the BSSE corrected value for the former case is $-0.25 \mathrm{kcal} / \mathrm{mol}$ and that for the latter case is $-0.20 \mathrm{kcal} / \mathrm{mol}$. It appears that the sp diffusc function plays a major role in the limited region of basis set size due to the intramolecular BSSE.

The CP corrected results for the DFE in the case of using pure sp basis sets are not consistent with large basis set results. which implies that there are rentaining basis set incompleteness errors in the CP corrected results. Most of those basis set incompleteness errors disappear after adding one polarization function.

In the DFT calculations. the magnitude of BSSE is smaller than that of MP2 ones especially for the sniall basis. The effects of BSSE on relative energies are also smaller in DFT than in MP2.

B. 1,2-Dimethoxyethane (DME). We have performed the calculations for the DME molecule using the same procedure as the DFE case. The DME nolecule can be fomied by substituting $-\mathrm{OCH}_{3}$ for the $\mathrm{F}$ aton of DFE. The ground state structures of ttt and tgg2 conformers ( $t$ for trans- and $g$ for gauche- form) are shown in Figure 4. Ln DME. the energy differences anong conformers are obtained from the BDE_CPs of two $\mathrm{CH}_{2}\left(\mathrm{OCH}_{3}\right)$ fragments. The same energy differences can also be obtained by correcting the total energies of conformer with the corresponding BSSE calcu- 

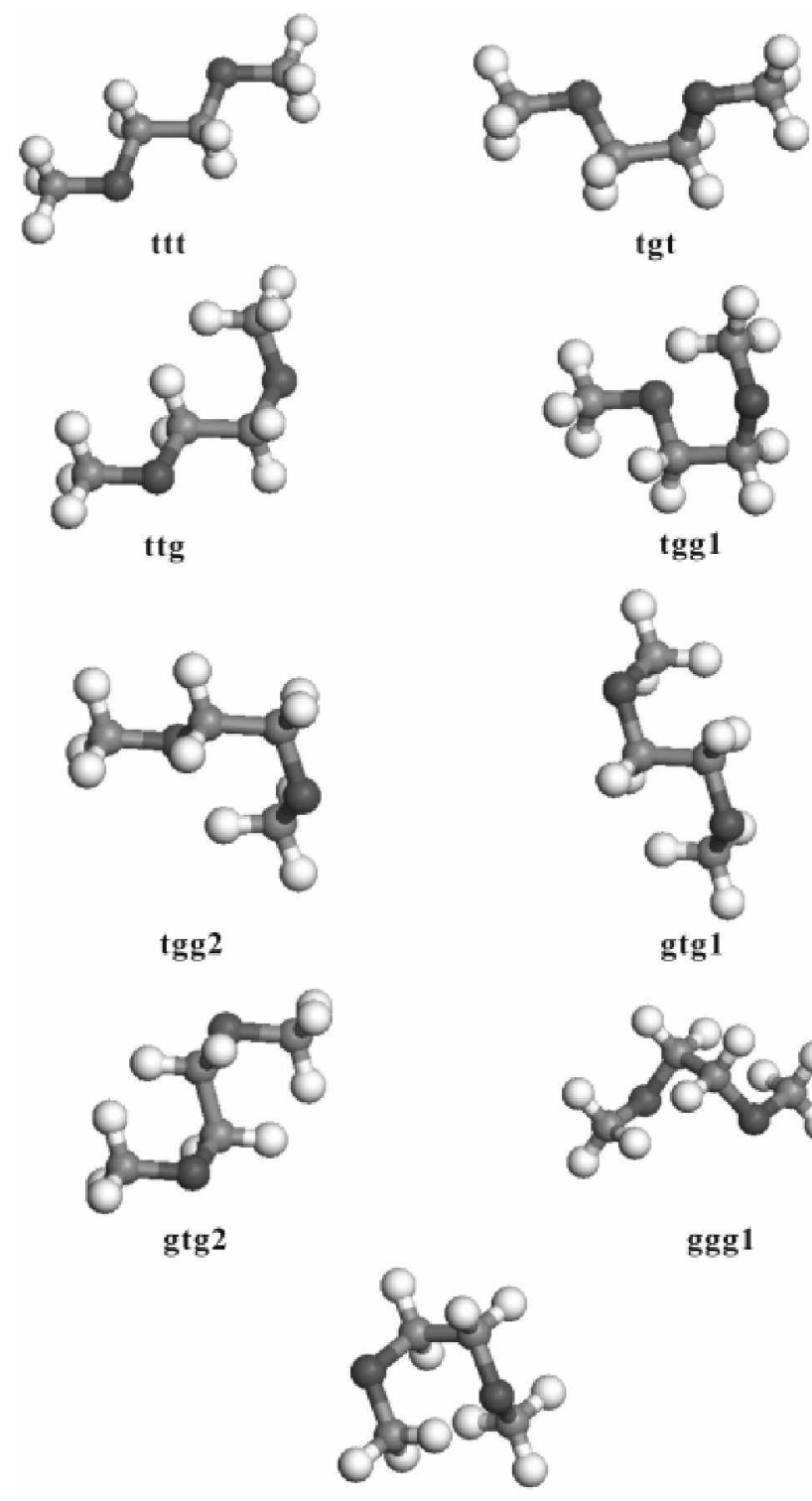

$\operatorname{ggg} 2$

Figure 4. The ttl. $\operatorname{tgl}$ llg. $\operatorname{lgg} 1, \operatorname{lgg} 2$, glgl, glg2, gggl, and ggg2 structures of 1,2-dimethoxyethane (DMF).

lated by Eq. (1) for each conformer. Jaffe et $a l^{+}$calculated the conformational properties of DME using $a b$ initio approaches by optimizing the molecule at the HF level of theory using $\mathrm{D} 95^{* *}$ basis set and performing the singlepoint energy calculations at the MP2 level of theory using the larger D $95+(2 \mathrm{df} . \mathrm{p})$ basis set. In order to estimate the pure BSSE effect. we reoptimized the molecule at the MP2/ D95** level and calculated MP2/D95+(2df.p) energies at the optimized geometries.

lable 2 summarizes the relative energies of various conformers compared to that of the ttt form. The MP2 energy differences between conformers are only slightly affected by the geometries employed. The MP2 energy differences calculated at the HF geometries from those at the MP2 ones by less than $0.18 \mathrm{kcal} / \mathrm{mol}$ as shown in Table 2. The estimated error originating from the intramolecular BSSE
Table 2. Calculated relative eneroies for various contomers of the DME: moleculs. Units arc in $\mathrm{keal} / \mathrm{mol}$

\begin{tabular}{|c|c|c|c|c|}
\hline $\begin{array}{l}\text { Contor- } \\
\text { mation }\end{array}$ & $\begin{array}{c}\mathrm{MP} 2 / \\
1995+(2 \mathrm{~d}, \mathrm{p}) \\
/ 11 \mathrm{~W} / 1) 45^{*}\end{array}$ & $\begin{array}{c}\mathrm{MP} 2 / \\
\mathrm{L}) 5 \overline{5}+(2 \mathrm{dl}, \mathrm{p}) \\
/ / \mathrm{MP} 2 / \mathrm{L}) 5^{-\infty}\end{array}$ & BSSF & $\begin{array}{c}\mathrm{MT} 2 / \\
195+(2 \mathrm{~d} / \mathrm{p})(\mathrm{CP})^{1} \\
/ / \mathrm{MP} 2 / \mathrm{L}) 5^{-\infty}\end{array}$ \\
\hline ttt & 0.00 & 0.010 & 000 & 000 \\
\hline $\operatorname{tg} t$ & 0.15 & 0.21 & 0.11 & 0.32 \\
\hline $\mathrm{ttg}$ & 1.43 & 1.47 & 0.10 & 1.57 \\
\hline $\operatorname{tg} g$ & 1.51 & 1.46 & 0.35 & 1.81 \\
\hline $\operatorname{tgg} 2$ & 0.23 & 0.29 & 0.40 & 0.69 \\
\hline gtg 1 & 3.31 & 3.07 & 0.13 & 3.20 \\
\hline $\operatorname{gtg} 2$ & 3.08 & 2.94 & 0.13 & 3.07 \\
\hline gggol & 1.64 & 1.46 & 0.31 & 1.77 \\
\hline ggg 2 & 1.86 & 1.82 & 0.19 & 2.01 \\
\hline
\end{tabular}

"The BSSE conected relative values emploving the CP procedure explained in the text.

becomes as large as $0.40 \mathrm{kcal} / \mathrm{mol}$. even for the $\mathrm{D} 95+(2 \mathrm{df} . \mathrm{p})$ basis set. Since the energy differences among conformers are in the range of $0.2-3.1 \mathrm{kcal} / \mathrm{mol}$. BSSE cannot be ignored in all cases. The magnitude of BSSE for the C-C bond of the conformers with the gauche conformations in the middle are generally larger than those with the trans ones. partly because the distances between $-\mathrm{OCH}_{3}$ fragments arc shorter in the former cases. The BSSE correction by the C.P method increases the relative cnergics in all cases. indicating that the intramolccular BSSE is minimum for the ground tll structure among the conlormers.

The relative populations of conformers from the simple Boltzmann distribution cquation at $273.15 \mathrm{~K}$ are listed in

Table 3. Relative populations of DMF contormers at $0{ }^{\circ} \mathrm{C}$

\begin{tabular}{|c|c|c|c|}
\hline $\begin{array}{l}\text { Conformation } \\
\text { (degeneracy) }\end{array}$ & $\begin{array}{c}\mathrm{MP} 2 / \\
\mathrm{L} 95+(2 \mathrm{di}, \mathrm{p}) \\
/ / 1 \mathrm{~L}^{\mathrm{i} / \mathrm{D}} 95^{* *}\end{array}$ & $\begin{array}{c}\mathrm{MP} 2 / \\
\mathrm{L} 95+(2 \mathrm{dI}, \mathrm{p}) \\
/ / \mathrm{MP} 2 / \mathrm{D} 95^{* *}\end{array}$ & $\begin{array}{c}\text { MP2/ } \\
\text { D95+(2alip)(CP) } \\
\text { /MP2/L95 }\end{array}$ \\
\hline $\operatorname{ttt}(1)$ & 1.00 & 1.00 & 1.00 \\
\hline $\operatorname{tg} t(2)$ & 1.55 & 1.36 & 1.11 \\
\hline $\operatorname{tg}(4)$ & 0.29 & 0.27 & 0.22 \\
\hline $\operatorname{lgg} l(4)$ & 0.25 & 0.27 & 0.14 \\
\hline $\operatorname{lgg} 2(4)$ & 2.62 & 2.34 & 1.12 \\
\hline $\mathrm{g} \lg l(2)$ & 0.01 & 001 & 0.01 \\
\hline $\operatorname{glg} 2(2)$ & 0.01 & 0.01 & 0.01 \\
\hline $\operatorname{gggl}(2)$ & 0.10 & 0.14 & 0.08 \\
\hline $\operatorname{ggg} 2(4)$ & 0.13 & 0.14 & 0.10 \\
\hline
\end{tabular}

"The BSSF. corrected relative values cmplosing the CP procedure explained in the text.

Table 4 . The relative energies of the tgt and tog 2 torms to the tth conformer for the DMF. molecule using various hasis sets at the MP2/D95** goometrics. Units are kal/mol

\begin{tabular}{|c|c|c|c|c|}
\hline Conlomation & $\begin{array}{l}\mathrm{D} 9 \mathrm{~s}+ \\
(2 \mathrm{~d} p)\end{array}$ & $\begin{array}{l}\text { Dos+ } \\
(2 d: 2 p)\end{array}$ & $\begin{array}{c}\text { Dojo+t } \\
(2 \mathrm{~d} p) \text { ) }\end{array}$ & 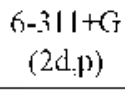 \\
\hline $\mathrm{ttt}$ & 0000 & 0,000 & 0000 & 0.000 \\
\hline tgt & 0.297 & 0.376 & 0.272 & 0.281 \\
\hline $\operatorname{tgg} 2$ & 0.235 & 0.235 & 0.241 & 0.34 \\
\hline
\end{tabular}


Table 3 using encrgies w ith and without BSSE corrections. The population changes are remarkable in two $\operatorname{tgg}$ forms. In particular. the $\operatorname{tgg} 2$ population calculated as the most popular conformer withoul BSSE corrections $s^{4.15}$ is reduced by a factor of about 2. and becomes similar to $1 \mathrm{gl}$ or $\mathrm{tt} 1 \mathrm{popu}-$ lations.

To the best of our knowledge. the appropriate correction procedure for the intramolccular BSSE has not been presented at the correlated levels of theory. Although there are limitations and arbitrariness in the present approach of treating only the central $\mathrm{C}-\mathrm{C}$ bond to be regarded as a gencral method of estimating the intramolecular BSSE. we have demonstrated that the systematic studies on the oncparticle basis set effects on conformational energy difference are possible and could be important.

The previous study of DME by Jaffe et $a l^{+}$tested the basis set performance only for the relative energics of the tgt form to the tht one. We have also included the $\operatorname{lgg} 2$ form as well as the $1 \mathrm{~g} 1 \mathrm{conformer}$ in the basis set study as summarized in Table 4. Although the relative energies of the tgi conformer do not vary substantially with the change of the basis sets. which is in line with Jaffe et $a$ /, $\mathrm{s}$ results. the enlargenent of the basis set to triple- $/$ cta quality increases the relatice energy of the tgg2 conformer from $0.229 \mathrm{kcal} / \mathrm{mol}$ to 0.534 $\mathrm{kcal} / \mathrm{mol}$

\section{Conclusions}

We have investigated the effect of the intramolecular BSSE in the conformational energy differences for the DFE and the DME molecules. The BSSE efrects on the energy: difference between two local minima. gauche and anti structures. of DFE are small. less than $0.2 \mathrm{kcal} / \mathrm{mol}$. for the the basis scts of various sizes. The cstimated BSSE becomes as large as $0.40 \mathrm{kcal} / \mathrm{mol}$ in the DME case. cren for the extended basis set of $\mathrm{D} 95+(2 \mathrm{dr}$. $)$. According to the present estimate. the intramolecular BSSE can become a source of error in the evaluation of the conformational energy differences even for the molecules of the moderate size such as DME. Whenever there are many conformations in the same energy range a careful estimate of BSSE is highly desirable.
Acknowledgment. This research is in part supported by KOSEF (1999-2-121-005-3) and Center for Nanotube and Nanostructure Compositc. Computational time was provided by KISTI.

\section{References}

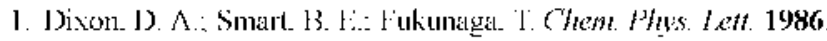
125. 447

2. Wiberg, K. B.: Murcko. M. A : I aidig, K. H.: Macl)ougall. P. I. J. Phes. $67 \mathrm{~cm} .1990 .94 .6956$.

3. Allinger. N. L.: Grev. R. S.: Yates. B. F.: Schacter III. H. F. J. Am. Chem Soc, 1990. 112.114.

4. Jalfè. R. I,.: Smith, (i. I): Yoon. 1). Y. J. Phos. (hom. 1993. 97. 12745 .

5. Chen Y.: Paddison. S. J: Tschuikon-Roux, I. J. Phys. Chem 1994. 28.1100.

6. Boys. S. F.: Bcrmardi. F. Mol. Phys. 1970. 19. 553

7. Van Diujneveldt. F. B.: Van Diujneveldt-van de Rijdt. J. G. C. M.: van I enthe J. II Chem Rey 1994,94. 1873

8. Xantheas. S.S. J. Chem Hows. 1996, 104,8821

9. Maser I.: Surjart. P. R. (Them. Phns Lkt 1992. 191. 497.

10. Davison. E. R.: Chakravorț. S. J. Ghem. Phys. Lett. 1994. 217. 48.

11. Gutowski. M.. Szezesniak. M. M.: Chalasinski. G. Chem. Ihts. lett. 1995, 24I. 140.

12. Davison. 1:. R. Chakraworty S. I. Chem Phs Lett 1945, 241. 146 .

13. (a) Lec. C.: Yang. W. Parr. R. G. Phns. Rev: B 1998. 37. 785. (b) Becke. A. D. J. Chem. Phis 1993. 98.5648.

14. Frisch. M. J.: Trucks. G. W.: Schlegel. H. B.: Scuscria. G. E.: Robb. M. A.: Cheesemam. I. R.: /akr/ewski. V. G.: Montgomers It.. J. A. Stratmann, R. H.: Burant. J. C.: I)apprich. S.: Millam. J. M: 1)aniels. A 1 ): Kudin. K. N : Strain, M. C : Farkats, O : Tomasi. T.: Barone. V: Cossi. M.: Cammi. R.: Mennucci. B.: Ponclli. C.: Adamo. C.: Clitford. S.: Oehterski. I.: Petersson. G. A.: Ayala. P. Cui. Y: Morokuma. Q.: Salvador. K. P.: Damenberg . I. J: Malick. I). K.: Rabuck. A. I): Raghavaturi. K. lioresman. I. 13: Cioslowsti. I. Orti\% I. V. I3aboul. A. G.: Stelanov. 13. J3.: I ilu. G.: J iathenko. A.: Piskory. P.: Komaromi. I.: Gomperts. R.: Martin. R. L.: Fox. D.: Keith. I. T.: Al-Laham. M. A.: Peng. C. Y.: Nanayakkara. A.: Challacombe. M.: Gill. P. M. W.: Johnson. B.: Chen. W.: Wong. M. W.: Andres. J. L.: Gonzalcz. C.. I Iead-Gordon. M.: Replogle. F. S.: Pople. I. A. Cattsitan 98 (Revision. I. Ix) Gaussian. Inc: Pittsurgh. PN 2001

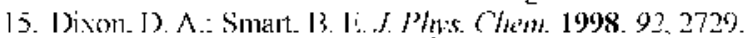

16. Tsuzuki. S.: Uelhimaru. T.: Tanabe. K: Hirano. T. $J$ Phis. Chem. 1993. 97.1346. 